\title{
Evaluation of the mechanical properties of sawdust, oil bean pod filler, raffia palm fibre and $\mathrm{CaCO}_{3}$ filled/epoxy hybridized composite
}

\author{
Akpenyi-Aboh, O.N. ${ }^{1}$ and Tachere, O. Z. ${ }^{2 *}$ \\ 1Department of Mechanical Engineering Technology, Delta state polytechnic, Ozoro, Nigeria. \\ 2Department of Civil Engineering Technology, Delta state polytechnic, Ozoro, Nigeria. \\ *Corresponding author. Email: ziontahere@gmail.com
}

Copyright (C) 2021 Akpenyi-Aboh and Tachere. This article remains permanently open access under the terms of the Creative Commons Attribution License 4.0, which permits unrestricted use, distribution, and reproduction in any medium, provided the original work is properly cited.

Received 6th April, 2021; Accepted 28th April, 2021

\begin{abstract}
This work was carried out to develop green composite from organic materials which are cheaply available within Nigeria. This study deals with the hybridization of epoxy composite with different organic materials. Five diffident composites were produced with the hybridization of matrix, sawdust (SD), raffia palm fibre (RPF), oil bean pod filler (OBPF) and calcium carbonate $\left(\mathrm{CaCO}_{3}\right)$ mixed at different volume. The composite samples were produced through the hand layup method, and their tensile and flexural properties, determined in accordance to ASTM International procedures. Results obtained from the laboratory tests indicated that the reinforcement materials greatly influenced the mechanical properties of the composite samples. The result revealed that the hybrid composite of $\mathrm{SD}, \mathrm{CaCO}_{3}$ and $\mathrm{RPF}$ had the best, compared to the other composite with different reinforcement materials. Similarly, it was observed that the composite produced with SD, OBPF and RPF had better tensile and flexural properties as compared to the composite reinforced with SD and $\mathrm{CaCO}_{3}$. This study affirmed that organic materials can be used to replace inorganic material $\left(\mathrm{CaCO}_{3}\right)$, hence the actualization of green composite is practically feasible.
\end{abstract}

Keywords: Calcium carbonate, green composites, hybridization, organic material, raffia palm fibre.

\section{INTRODUCTION}

Composites are produced by the combination of two or more different materials to form a superior material with unique engineering qualities and distinct advantages (Kandpal et al., 2015). Composites' materials are widely used in several sectors; as they are used in the automobile, sporting, textile, marine, electrical industries etc. Some major advantages of composite are lightweight, flexibility, non-corrosive and low maintenance cost (Uguru and Umurhurhu, 2018). Environmental safety is becoming a concern to human beings due to increase in environmental pollution, caused by the utilization of synthetic materials in constructional works. Most of these synthetic materials are highly poisonous to the environment, and the same time they are nonbiodegradable (Kandpal et al., 2015; Uguru and Oghenerukevwe, 2021). Green composites are produced when the components is derived from natural resources
(Goyal et al., 2014). These composite materials are biodegradable; hence they are easily converted into useful or harmless compounds by microorganisms. According to Kandpal et al. (2015), green composite can be classified into two major categories, which are: totally renewable composites where both the matrix and reinforcement material(s) are organic materials, partly renewable composites where the matrix or the reinforcement material(s) is organic materials.

African oil bean (Pentaclethra macrophylla Benth) tree belongs to the Leguminosae (Mimosoideae) family. The tree bears seeds which are enclosed in pods, which are 36 to $46 \mathrm{~cm}$ long. The matured pods have some medicinal values, and are also used as source of fuel in the rural area (Archinewhu, 1996; Oghenerukewve and Uguru, 2018). According to Uguru and Umurhurhu (2018), raffia palms (Raphia) are palms native to tropical regions of Africa, and 
its fibre obtained from the membrane located underside of the palm frond. Raffia fibre is widely utilized in the textile industry due to its high tensile strength (Tucker et al., 2010).

The environmental friendliness of biomaterials has increased their utilization in composite production. Several researches had been done on green composites, and their results were comparatively better than some of the composites produced from synthetic materials. Mishra et al. (2003) studied the engineering properties of pineapple leaf fiber (PALF) and sisal reinforced polyester composites and observed an improved in the tensile and flexural properties of the hybridized composites, which was further enhance with the incorporation of glass fibers in the composites. Similarly, Sapuan et al. (2013) reported that reinforcing polyester resin with glass and sugar palm fibres, produced composites with better tensile and flexural properties, which can used in the automobile and aerospace industries. Investigation into the flexural properties of raffia palm fibre, reinforced cement composite was carried out by Odera et al. (2014). It was observed that the incorporation of raffia palm fibre into cement matrix increased the flexural strength of the composite produced by over $100 \%$, when compared with the control experimental unit ( $0 \%$ raffia fibre volume). Likewise, Aji et al. (2012) studied some mechanical properties of kenaf/PALF fibres hybridized polyethylene composites, and reported that the fibres volume and size had significant effect on the mechanical properties of the hybridized composites.

The mechanical properties of the composite are greatly influenced by the mechanical properties and volume of the constituent materials. A study by Raju and Kumarappa (2012) revealed that the tensile and flexural strength of green composite produced from groundnut shell fillers and epoxy resin, generally increased with increased in the fillers volume. Azizi et al. (2011) reported that the swelling and water absorption rates, modulus of rupture and internal bond of composites produced from wheat straw and waste veneer splinters were decreased accordingly as the wheat straw volume increases. According to Lee and Waas (1999), the knowledge of the compressive strength of the reinforcement materials, is essential for the production of composite materials that can meet the expected area of utilization. Although several works had been done on the hybridization of green composites, there is still information dearth on oil bean shell pod shell filler (OBPF), sawdust (SD), raffia palm fibre (RPF) and calcium carbonate $\left(\mathrm{CaCO}_{3}\right)$ filled/epoxy hybridized composite. Therefore, the objective of this study is to evaluate the mechanical properties of sawdust, oil bean pod filler, raffia palm fibre and $\mathrm{CaCO}_{3}$ filled/epoxy hybridized composite The results obtained from this work will be helpful in the production of green composites for industrial use.

\section{MATERIALS AND METHODS}

The calcium carbonate filler used for this study was obtained from a chemical shop at Onitsha, Anambra State Nigeria. The raffia palm fibre was obtained from local farmer in Delta State of Nigeria. The sawdust was obtained from sawmill; while the oil bean shell pod shell filler was prepared by pulverizing and sieving of the oil bean pod shells. The matrix materials; epoxy resin (LY556) and the hardener (HY951) were procured from a chemical shop at Onitsha, Anambra State Nigeria.

\section{Chemical treatment}

The raffia fibre was immersed in $5 \% \mathrm{NaOH}$ solution for one hour, under ambient room temperature. After which the treated fibre was washed under running tap water for 20 minutes to remove all the $\mathrm{NaOH}$ from it, before sun drying for 24 hours. Then the dried treated fibre was chopped into dimension size (length) of $25 \mathrm{~mm}$.

\section{Composite production}

The hand lay-up composite production method was adopted in this study. Before the composite were casted, the moulds were oiled to facilitate the release of the composite from the moulds. During the composite production, measured quantity of the resin and the reinforcement materials (as stated in Table 1), apart from the raffia palm fibre, were poured into a container, and stirred vigorously for 20 minutes to obtain a uniform mixture. Then the right volume of the hardener was poured into the mixture, stirred thoroughly for another 10 minutes, and poured into the already prepared moulds. The matrix was prepared by mixing the epoxy resin and hardener at the ratio of 8:2.

In the production of the composite reinforced with RPF, the mould was filled with the matrix and the other reinforcement materials up to $25 \%$ of its depth, the RPF was uniformly spread on top of the mixture, and then the mould was filled up with the mixture. All the casted composites were covered with plastic sheet, and $10 \mathrm{~kg}$ weight was placed on top of each mould for 24 hours, to minimized void formation within the casted composite. The composite was de-moulded after 24 hours, and cured at ambient temperature for one week. Table 1 presents the composition of the hybridized composite investigated in this study.

\section{Material testing}

\section{Tensile test}

The tensile properties of the samples were tested according to ASTM D368 procedure. During the test, each end of the composite sample was gripped by the machine, and pulled slowly at a speed of $1 \mathrm{~mm} / \mathrm{min}$, until rupture point (Uguru and Oghenerukevwe, 2021). Tensile strength 
Table 1. Composite composition

\begin{tabular}{ll}
\hline Code & Composition \\
\hline S1 & $80 \%$ matrix $+10 \%$ sawdust $+10 \%$ RPF \\
S2 & $80 \%$ matrix $+10 \%$ sawdust $+5 \%$ OBPF $+5 \%$ RPF \\
S3 & $80 \%$ matrix $+10 \%$ sawdust $+5 \% \mathrm{CaCO}_{3}+5 \%$ RPF \\
S4 & $80 \%$ matrix $+10 \%$ sawdust $+5 \% \mathrm{CaCO}_{3}+5 \%$ OBPF \\
S5 & $80 \%$ matrix $+10 \%$ sawdust $+10 \% \mathrm{CaCO}_{3}$ \\
\hline
\end{tabular}

and elongation at break of each composite sample were calculated with the expressions given in Equations 1 and 2 , as recommended by Uguru and Oghenerukevwe (2021).

Tensile strength, $\sigma=\frac{\text { Force }_{\text {Max }}}{\text { Area }}$

Elongation at Break, $\mathrm{EB}(\%)=\frac{\Delta \mathrm{L}}{\mathrm{L}}$

2

Where: $\Delta \mathrm{L}=$ extension at break point, $\mathrm{L}=$ original length of the sample, $F_{\max }=$ maximum load applied to the sample.

\section{Flexural test}

This was done in accordance to ASTM: D790 procedure, using the three points loading setup. The machine loads the middle of the samples until it fractures. During the loading process, a force-deformation curve was plotted automatically by the microprocessor attached to the machine.

\section{Statistical analysis}

Data gotten from the laboratory tests were statistical analyzed by using the Microsoft excel software.

\section{RESULTS AND DISCUSSION}

\section{Tensile strength}

The results of the tensile test presented in Figure 1 indicated that the reinforcement material influenced the tensile strength of the composite samples. The composite reinforced with $10 \%$ sawdust, $5 \% \mathrm{CaCO}_{3}$ and $5 \%$ OBPF had the lowest tensile strength $(18.45 \mathrm{MPa})$, while the composite reinforced with $10 \%$ sawdust, $5 \% \mathrm{CaCO} 3$ and $5 \%$ RPF had the highest tensile strength of $31.55 \mathrm{MPa}$. It was observed from the results that the composite reinforced with RPF (S1, S2 and S3) had higher tensile strength, than the composite without RPF reinforcement (S4 and S5). This conforms to previous research results (Velmurugan and Manikandan, 2007; Sanjay and
Yogesha, 2016; Edafiadhe et al., 2019) that, fibres enhanced tensile strength of composites more than fillers. Similar results were obtained by Wicaksono et al. (2019). According to Wicaksono et al. (2019), the tensile strength of hybridized polyester composite reinforced with $\mathrm{CaCO}_{3}$ and kenaf fiber was higher than the composite reinforced with only $\mathrm{CaCO}_{3}$ or kenaf fibre.

\section{Tensile elongation}

The results of the tensile elongation of the hybridized composite samples are presented in Figure 2. It was observed from the results that the tensile elongation of the composite varied widely, depending on the reinforcement material used for the composite production. The maximum tensile elongation $(15.2 \mathrm{~mm})$ was observed in the S3 samples, while the least tensile elongation $(10.3 \mathrm{~mm})$ was observed in the S5 samples. Generally, the tensile elongation of the S1, S2 and S3 composite samples, were higher than the tensile elongation of the S4 and S5 composite samples. This revealed that RPF has significant impact on the tensile elongation of the composite samples. These results are in similar tread to the once previously obtained by Nyior et al. (2018). Nyior et al. (2018) reported that the tensile elongation of epoxy composites was enhanced by the incorporation of low volume (less than $20 \%$ ) of raffia palm fibre and groundnut shell filler. The general poor tensile properties recorded in S4 and S5 could be attributed to the fillers volume incorporated into the composite sample. According to Turmanova et al. (2012) and Akpokodje et al. (2021), high fillers to matrix ratio will lead to weaker interactions between the filler and the matrix, which will result in the production of composites with poor tensile and compressive properties.

\section{Flexural strength}

The results obtained from the flexural strength test of the composite sample are presented in Figure 3. As obtained from Figure 3 , the flexural strength of the composite samples was influenced by the type of reinforcement material used. It was observed that the composite reinforced with $10 \%$ sawdust, $5 \% \mathrm{CaCO}_{3}$ and $5 \% \mathrm{RPF}$ had the highest flexural strength of $49.2 \mathrm{MPa}$. In contrast, the composite produced with $10 \%$ sawdust $+5 \% \mathrm{CaCO}_{3}+5 \%$ 


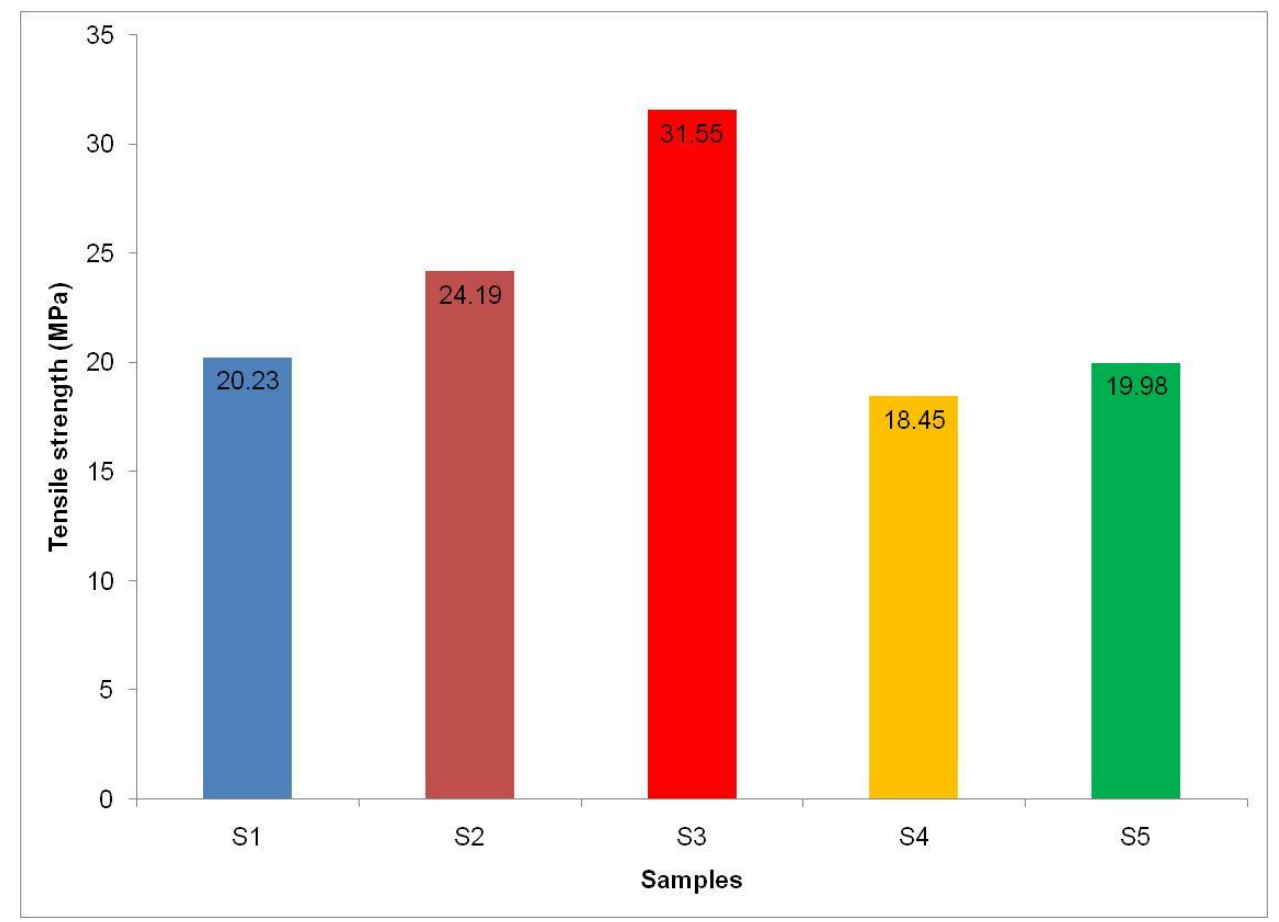

Figure 1. Tensile strength of the hybridized composite.

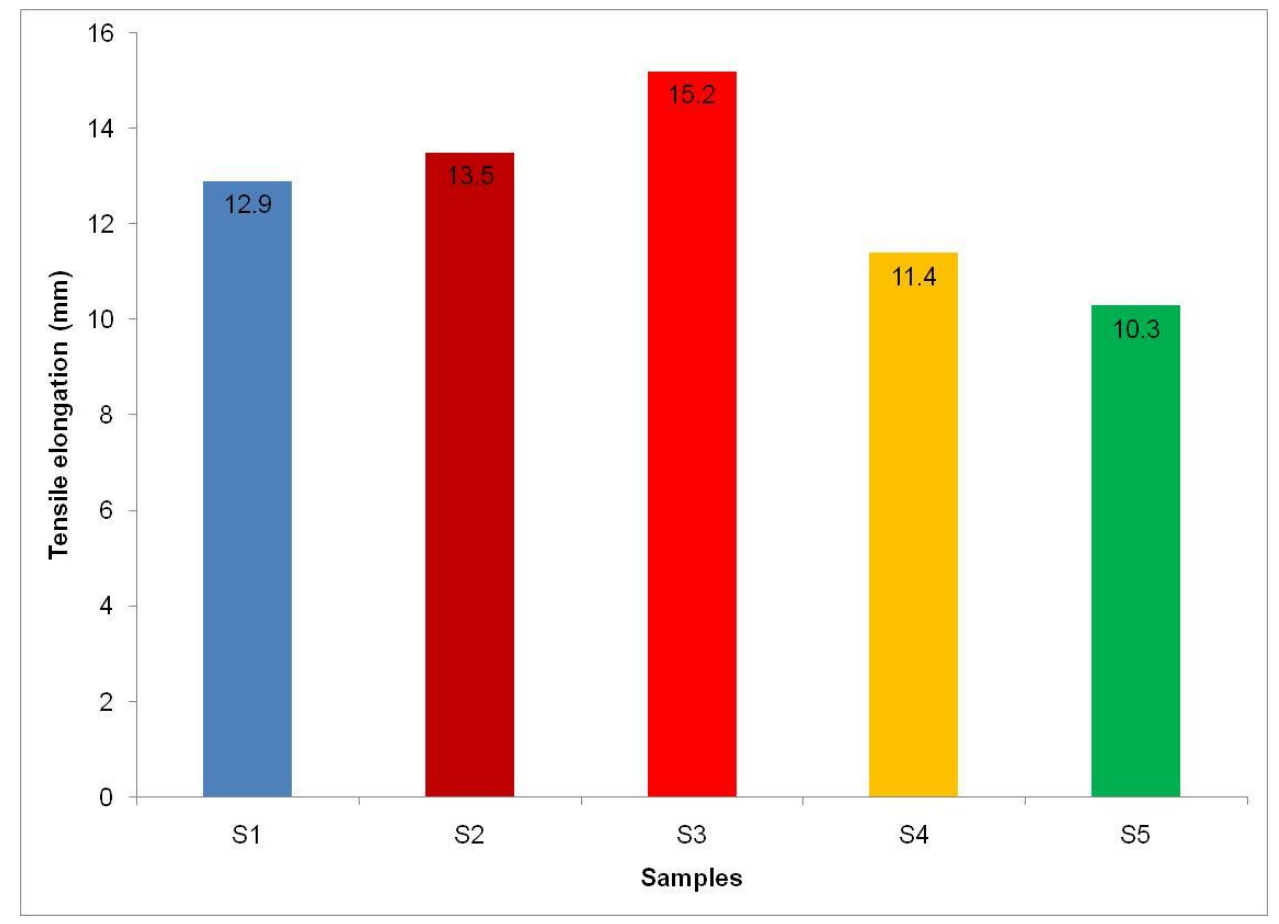

Figure 2. Tensile elongation of the hybridized composite.

OBPF had the lowest flexural strength of 22.8 MPa. It was observed from the results that composite samples (S1, S2, S3) incorporated with RPF had higher flexural strengths, compared to the composite samples (S4 and S5) produced without the incorporation of RPF. This portrayed that the RPF played an essential role in enhancing the flexural strength of the composite samples. This result is similarly to previous research work of Motaleb et al. (2018), 


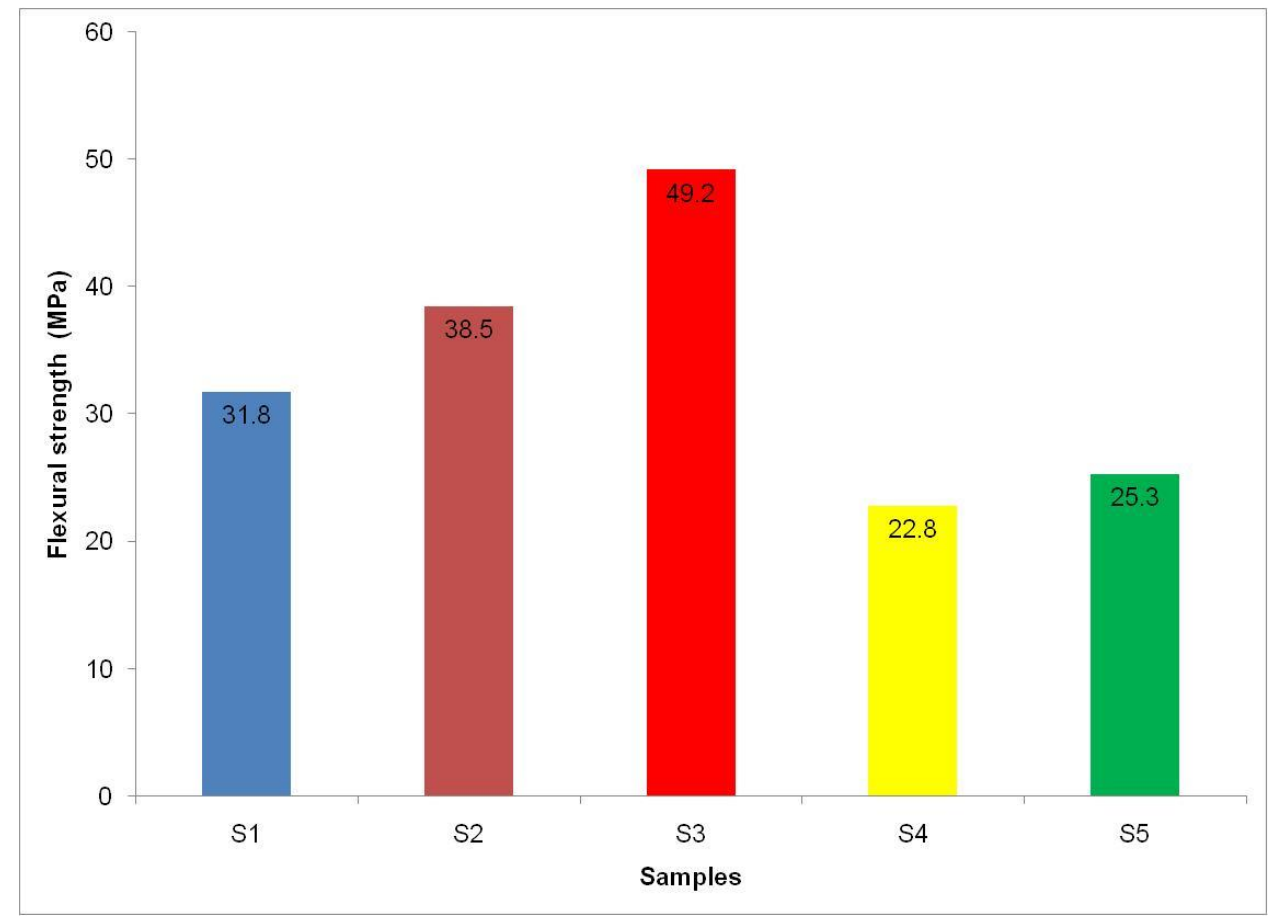

Figure 3. Flexural strength of the hybridized composite.

who reported that PALF enhances the flexural properties of composite samples. Motaleb et al. (2018) stated that the flexural strength and flexural modulus of PALF reinforced composite increased 155 and 265\%, respectively. Similarly, Sapuan et al. (2005) observed that the flexural strength of coconut fibre reinforced epoxy composite samples was higher than the control unit. Furthermore, according to Oghenerukewve and Uguru (2018), the rupture strength and bending modulus of epoxy resin were enhanced through the hybridization of sawdust and oil bean shell filler. As seen in the results, the combination of $\mathrm{SD}, \mathrm{OBPF}$ and RPF can be used to produce hybridized composite, with better tensile and flexural qualities. This showed that the combination of SD, OBPF and RPF which are organic materials, can be used to replace $\mathrm{CaCO}_{3}$ which is an inorganic materials. This actualized the aim of producing and utilizing green and environmental friendly composites for diversified engineering applications.

\section{Conclusion}

This study deals with the production of green composite that can be utilized from various engineering applications. Hybridized composite samples were produced from SD, OBPF, $\mathrm{CaCO}_{3}$ and RPF at different volume. All the composite samples produced were subjected to tensile and flexural test, in accordance to ASTM International standards. Results obtained from the tests depicted that the composite hybridized with $\mathrm{SD}, \mathrm{CaCO}_{3}$ and $\mathrm{RPF}$ had the best tensile and flexural properties. In contrast, the results showed that the composite produced with $\mathrm{SD}$, $\mathrm{CaCO}_{3}$ and OBPF had the lowest tensile and flexural properties. Additionally, the study revealed that the composite hybridized with SD, OBPF and RPF developed better tensile and flexural properties, than the composite produced from $\mathrm{SD}$ and $\mathrm{CaCO}_{3}$. This showed that $\mathrm{SD}$, OBPF and RPF can be used in the production of green composite for diversified engineering applications.

\section{CONFLICT OF INTEREST}

The authors declare that they have no conflict of interest.

\section{REFERENCES}

Aji, I. S., Zainudin, E. S., Sapuan, S. M., Khalina, A., \& Khairul, M. D. (2012), Study of hybridized kenaf/PALF-reinforced hdpecomposites by dynamic mechanical analysis. PolymerPlastics Technology and Engineering, 51(2), 146-153.

Akpokodje, O. I. Agbi, G. G., Uguru, H., \& Nyorere, O. (2021). Evaluation of the compressive strength of commercial sandcrete blocks produced in two metropolises of Delta State, Nigeria. Applied Journal of Physical Science. 3(2), 61-71.

Archinewhu, S. C. (1996) The African oil bean (Pentaclethra macrophylla Benth.). In: Nwokolo, E., Smartt, J. (eds.). Food and feed from legumes and oilseeds. Springer, Boston, MA

Azizi, K., Tabarsa, T., \& Ashori, A. (2011). Performance characterizations of particleboards made with wheat straw and waste veneer splinters. Composites Part B: Engineering, 42(7), 2085-2089.

Edafiadhe, E. O., Nyorere, O., \& Uguru, H. (2019). Compressive 
behaviours of oil bean shell and wood particulates/ epoxy composite board. Archives of Current Research International, 16(3), 1-8.

Goyal, K. K., Jain, V., \& Kumari, S. (2014). Prediction of optimal process parameters for abrasive assisted drilling of SS304. Procedia Materials Science, 6, 1572-1579.

Kandpal, B. C., Chaurasia, R., \& Khurana, V. (2015). Recent advances in green composites - A Review. International Journal for Technological Research in Engineering, 2(7), 742747.

Lee, S. H., \& Waas, A. M. (1999). Compressive response and failure of fiber reinforced unidirectional composites. International Journal of Fracture, 100(3), 275306.

Mishra, S., Mohanty, A. K., Drzal, L. T., Misra, M., Parija, S., Nayak, S. K., \& Tripathy, S. S. (2003) Studies on mechanical performance of biofiber/glass reinforced polyester hybrid composites. Composites Science and Technology, 63(10), 1377-1385.

Motaleb, K. Z. M., Islam, M., \& Hoque, M. B. (2018). Improvement of physicomechanical properties of pineapple leaf fiber reinforced composite. International Journal of Biomaterials, 2018, Article ID 7384360.

Nyior, G. B., Aye, S. A., \& Tile, S. E. (2018). Study of mechanical properties of raffia palm fibre/groundnut shell reinforced epoxy hybrid composites. Journal of Minerals and Materials Characterization and Engineering, 6(2), 179-192.

Odera, R. S., Onukwuli, O. D., \& Osoka, E. C. (2011). Optimization of the flexural strength of raffia palm fibre-cement composites. Journal of Emerging Trends in Engineering and Applied Sciences, 2(2), 294-297.

Oghenerukewve, P. O., \& Uguru, H. (2018). Effect of fillers loading on the mechanical properties of hardwood sawdust/oil bean shell reinforced epoxy hybrid composites. International Journal of Scientific Research in Science, Engineering and Technology, 4(8), 620-626.

Raju, G. U., \& Kumarappa, S. (2012). Experimental study on mechanical properties of groundnut shell particle reinforced epoxy composites. Journal of Reinforced Plastics and Composites, 30(11), 1029-1037.
Sanjay, M. A., \& Yogesha, B. (2016). Studies on mechanical properties of jute/E-glass fiber reinforced epoxy hybrid composites. Journal of Minerals and materials Characterization and Engineering, 4(1), 15-25.

Sapuan, S. M., Lok, H. Y., Ishak, M. R., \& Misri, S. (2013). Mechanical properties of hybrid glass/sugar palm fibre reinforced unsaturated polyester composites. Chinese Journal of Polymer Science, 31(10), 1394-1403.

Sapuan, S. M., Zan, M. N. M., Zainudin, E. S., \& Arora, P.J. (2005). Tensile and flexural strengths of coconut spathe-fibre reinforced epoxy composites. Journal of Tropical Agriculture, 43(1-2), 63-65.

Turmanova, S., Genieva, S., \& Vlaev. L (2012). Obtaining some polymer composites filled with rice husks ash-a review. International Journal of Chemistry, 4(4), 75-84.

Uguru, H. \& Oghenerukevwe, P. (2021). Effect of organic fillers on the tensile characterization of calcium carbonate hybridized epoxy composite. Direct Research Journal of Engineering and Information Technology. 8, 42-48.

Uguru, H., \& Umurhurhu, B. (2018). Effect of alkaline treatment on tensile properties of raffia palm fibre. Direct Research Journal of Engineering and Information Technology, 5(4), 2831.

Velmurugan, R., \& Manikandan, V. (2007). Mechanical properties of palmyra/glass fiber hybrid composites. Composites Part A: Applied Science and Manufacturing, 38(10), 2216-2226.

Wicaksono, S. T., Laksana, A. H., \& Ardhyananta, H. (2019, June). Effect of calcium carbonate on the tensile and density properties of kenaf/polyester hybrid composite. In: IOP Conference Series: Materials Science and Engineering, 546, 1-5. 